\title{
Acute care nurses' attitudes toward family presence during cardio-pulmonary resuscitation in the Kingdom of Saudi Arabia
}

\author{
Suha Omran ${ }^{* 1}$, Nahla AL Ali ${ }^{2}$, Hassan Alshahrani ${ }^{3}$ \\ ${ }^{1}$ Adult Health Department/Faculty of Nursing, Jordan University of Science and Technology, Irbid, Jordan \\ ${ }^{2}$ Community and Mental Health Department, Jordan University of Science and Technology, Jordan \\ ${ }^{3}$ King Saud Medical City, Riyadh, Saudi Arabia
}

Received: February 4, 2015

Accepted: April 8, 2015

Online Published: April 27, 2015

DOI: $10.5430 /$ cns.v3n3p69

URL: http://dx.doi.org/10.5430/cns.v3n3p69

\begin{abstract}
Introduction: With the rise of family centered care, family involvement into healthcare decisions has increased and stringent visitation policies have relaxed, to the extent that family presence at bedside during invasive procedures and resuscitation (CPR) is now provided by some healthcare organizations. As such policies have become common practice in many countries, this study sought to explore the attitude of acute care nurses in the Kingdom of Saudi Arabia (KSA) toward family presence during cardiopulmonary resuscitation to enhance our understanding the potential consequences of implementing such policies.

Methods: A sample 192 acute care nurses were recruited using convenient sampling. Instruments used were Demographic Data Form, and the Family Presence Support Staff Assessment tool (FPSSAT).

Results: Results indicated that nurses had a positive attitude about family presence. Several answers emerged from the open ended question data. Major concerns of nurses were the safety of patients and patient' families, performance anxiety, emotional effects on families, and the endangerment of misplacing their abilities while caring for patients.

Conclusions: More research is needed on family presence during CPR in Saudi Arabia. Besides surveying healthcare providers, the attitudes of patients and families should be studied.
\end{abstract}

Key Words: Attitudes, Family presence during cardiopulmonary resuscitation, Family centered care

\section{INTRODUCTION}

Research done over several decades has increased our understating of the practice of allowing family members to be present during cardiopulmonary resuscitation (CPR) and its benefits. Family centered cares are endorsed and have been used to develop practice guidelines which are widely used by some healthcare organizations in the United States. As result, the American Association of Critical Care Nurses $(\mathrm{ACCN})$ issued a practice alert recommending that family members of patients undergoing invasive procedures or resus- citation should be provided with option of presence with their patients at the bedside. ${ }^{[1]}$ Despite support by professional organizations, few critical care units in the United States have written policies on allowing family presence. ${ }^{[2]}$ Family centered care is an approach in which care is provided not only to patients but also for patients' family. ${ }^{[3]}$ Available evidence suggest that when family centered care is properly and promptly provided it can reduce negative psychosocial outcomes for patients and their families. ${ }^{[3,4]}$ Family presence during resuscitation may address those psychosocial needs

\footnotetext{
*Correspondence: Suha Omran; Email: suha31@just.edu.jo; Address: Adult Health Department/Faculty of Nursing, Jordan University of Science and Technology, Irbid, Jordan.
} 
and provide family centered care. ${ }^{[4-6]}$

Experiencing the death of a family member is a traumatic experience; nevertheless, most patients would like their family members to be present during CPR. ${ }^{[7-10]}$ Apart from being physically and emotionally present with their patients, family members can feel how much healthcare providers care and what have been done to their patients which gives satisfaction to patients from their family members.

Viewpoints among healthcare providers regarding family presence during CPR have been divided. Despite the benefits of family presence and the plethora of scientific evidence about its effectiveness, some health care providers are hesitant to embrace family. Some health care providers believed that family presence during CPR would offend and traumatized family members and interfere with treatment procedures. ${ }^{[7,9-21]}$ On the other hand, some healthcare providers believe that family presence would benefit not only the patients but also family members. ${ }^{[22-24]}$ It has been reported that healthcare providers beliefs and attitudes toward family presence during resuscitation are affected by the levels of knowledge and awareness about family presence, and other factors such as profession (nurses has more favorable attitudes than physicians), ${ }^{[25]}$ length of professional experience, healthcare provider training, and previous experience with family presence during resuscitation/invasive procedure. ${ }^{[2]}$

There have been limited investigations on the attitudes of healthcare providers, on attitudes of healthcare providers toward family presence during resuscitation in Saudi Arabia. There has been striking evidence from studies of patients and their families, especially with respect to accepting data from studies of patients and their families show consistent trends toward acceptance and expectation of family presence, a limited number of studies show that healthcare providers to have mixed feelings toward family presence. This study provides insights into the attitudes of nurses in relation to family presence. Therefore, the aim of the study was to explore the attitude of acute care nurses in the Kingdom of Saudi Arabia (KSA) toward family presence during cardiopulmonary resuscitation. The study answered the following research questions: (1) What are the attitudes of acute care nurses in Saudi Arabia hospitals toward family presence during CPR? (2) Is there a relationship between KSA acute care nurses' attitude toward family presence during CPR and selected demographic variables (e.g. age, gender, level of education, experience and religion)?

\section{METHOdOLOGY}

The study used a descriptive and cross sectional design to collect data on all relevant variables. The study participants were recruited from the emergency department, intensive care units (ICU), and coronary care unit (CCU) of the largest hospitals in the five geographic regions (Central, Northern, Southern, Eastern, and Western parts) of Riyadh city, KSA via cluster sampling. A total of 192 participants responded to study questionnaire, with an $80 \%$ overall response rate (240 questionnaires distributed). In the hospitals, the participants were specifically recruited from the emergency department, ICU, and CCUs. The participants who were included were those who were: nurses with at least one year experience working with adult patients in ICU, CCU, and emergency department. Another inclusion criteria was the ability to read and write in English. Participants with prior experience with family presence were not excluded from the study.

\subsection{Data collection tool}

The instrument used to collect data was comprised of a Demographic Data Sheet (DDS) and The Family Presence Support Staff Assessment tool (FPSSAT). ${ }^{[26]}$ The DSS had item eliciting information about the participant's age, gender, marital status, education level, experience years of work, experience in critical care area, and religions. The FPSSAT has been designed to assess attitudes toward family presence during resuscitation and/or invasive procedures. The tool contains six items that elicit a response using five point Likert scale about the participant's ability to provide psychosocial and/or emotional support to family members during these procedures, five questions, ask for a yes or no response, four of which seek explanation to identify attitudes, concerns, and beliefs, as well as the current practices of individual staff, and two open ended questions that ask about barriers to family presence during resuscitation. Additional comments are solicited at the end of the questionnaire. Content validity of the tool used for this study was established by three experts in the field. The Cronbach $\alpha$ reliability coefficient for the first six items was 0.682 and it was 0.723 for the remaining questions. The original instrument was from ENA. Ellison obtained ENA's permission to utilize and amend the questionnaire. ${ }^{[26]}$ Consent was obtained from Ellison to utilize the tool. The original tool was changed by adding the question: "What are the other barriers to family presence?" "Why?".

\subsection{Data collection procedure}

The study was approved by the Public Administration for Training and Scholarships (Ministry of Health, KSA), and the administrative approval were gained from the five hospitals in Riyadh City (KSA). After obtaining approval and permission to conduct the study from the ethics committee and hospitals, the researchers approached Head Nurse (HN) of each unit (emergency, CCU and ICU) in the different hospitals to schedule the data collection activities. On a scheduled

ISSN 2324-7940 E-ISSN 2324-7959 
data collection days the research assistants who were nurses approached the participants working at these units to recruit them in the study. All participants were informed about the aim of the study, agreed to give the requested information, and gave informed consent. After the consent process the participants were taken in a private room to complete study questionnaires as part of the data collection.

\subsection{Data analysis}

The Statistical Package for Social Science Software (SPSS, version 20, Chicago, Inc.) was used for data processing and analysis. Characteristics of participants' variables were described using frequency distribution for categorical variables, mean and standard deviation for continuous variables. Total mean scores of family presence support staff assessment score (M-FPSSAT); was used to reflect the participants' attitudes towards family presence during CPR; the higher the M-FPSSAT, the more favorable the attitude of participants toward family presence. Independent $t$ tests, $\chi^{2}$ and analysis of variance was carried out for some variables.

\section{RESULTS}

The sample characteristics are summarized in Table 1. The sample of nurses $(n=192)$, consisted mainly of females (74\%), aged 20-28 (50\%), and with less than 10 years' experience (74\%). One third of nurses were Saudis (33\%), 34\% were Indians, and 20\% were Filipinos. Muslims comprised $51 \%$ of the sample, while $44 \%$ were Christians.
Table 1. Demographic characteristics $(\mathrm{N}=192)$

\begin{tabular}{|c|c|c|c|}
\hline Variables & Categories & Frequency & Percentage \\
\hline \multirow{3}{*}{ Age } & $20-28$ & 96 & 50 \\
\hline & $29-37$ & 69 & 36 \\
\hline & $38>55$ & 27 & 14 \\
\hline \multirow{2}{*}{ Gender } & Male & 50 & 26 \\
\hline & Female & 142 & 74 \\
\hline \multirow{4}{*}{ Nationality } & Indian & 66 & 34 \\
\hline & Filipino & 39 & 20 \\
\hline & Saudi & 64 & 33 \\
\hline & Other & 23 & 12 \\
\hline \multirow{2}{*}{ Marital Status } & Single & 86 & 45 \\
\hline & Married & 105 & 55 \\
\hline \multirow{3}{*}{ Religion } & Islam & 98 & 51 \\
\hline & Christian & 84 & 44 \\
\hline & Other & 10 & 5 \\
\hline \multirow{5}{*}{ Hospital D. } & Emergency & 54 & 28 \\
\hline & ICCU & 36 & 19 \\
\hline & ICU & 46 & 24 \\
\hline & trauma unit & 17 & 9 \\
\hline & Other & 39 & 20 \\
\hline \multirow{3}{*}{ Educational level } & Diploma & 131 & 68 \\
\hline & BSN & 57 & 30 \\
\hline & Postgraduate & 4 & 2 \\
\hline \multirow{2}{*}{ Experience } & $<10$ years & 142 & 74 \\
\hline & $>10$ years & 50 & 26 \\
\hline
\end{tabular}

Among nurses, 52\% $(n=104 / 192)$ had previous experiences with family presence, and $83 \%$ had CPR certificate (see Table 2).

Table 2. CPR variables $(\mathrm{N}=192)$

\begin{tabular}{llll}
\hline Variables & Categories & Frequency & Percentage (\%) \\
\hline Participated in CPR course & Yes & 59 & 30.9 \\
& No & 132 & 69.1 \\
CPR certificate & Yes & 160 & 83.3 \\
& No & 32 & 16.7 \\
CPR No. & $1-3$ time & 133 & 59.3 \\
& More than 3 time & 59 & 30.7 \\
Allowing FP & $1-3$ time & 93.4 \\
Family witnessed CPR & More than 3 time & 99 & 51.6 \\
Family presence option applied in hospital & $1-3$ time & 69 & 48.4 \\
& More than 3 time & 31 & 51.6 \\
\hline
\end{tabular}

\subsection{Nurses attitudes toward family presence during CPR}

Overall, nurses had a favorable attitude toward family presence $($ M-FPSSAT $=20.6, S D=3.87$, mean scores ranged $=$
6-30). The (FPSSAT) is divided into two sub scales; the first consists of six questions, A 5point Likert scale measuring how the participants provide psychosocial and emotional support for the patients and their families during CPR, and 
a sub-scale consisting of 8 questions, yes/no answers and ence during CPR. Participants scored 21 out of 30 on the that measures the participant's attitude toward family pres- emotional and psychological sub scale (see Table 3).

Table 3. Staff attitude towards family presence during CPR $(\mathrm{N}=192)$

\begin{tabular}{|c|c|c|c|}
\hline Questions & Response & $\mathbf{N}$ & $\%$ \\
\hline \multirow{2}{*}{$\begin{array}{l}\text { Have you participated in a treatment situation in which a family member was present } \\
\text { during the performance of invasive procedure }\end{array}$} & Yes & 190 & 99 \\
\hline & No & 2 & 1.0 \\
\hline \multirow{2}{*}{$\begin{array}{l}\text { Have you participated in a treatment situation in which a family member was present } \\
\text { during the performance of CPR. }\end{array}$} & Yes & 81 & 42.2 \\
\hline & No & 111 & 57.8 \\
\hline \multirow{2}{*}{$\begin{array}{l}\text { Has your job performance ever been hampered by the presence of a patient's family } \\
\text { member? }\end{array}$} & Yes & 113 & 58.9 \\
\hline & No & 79 & 41.1 \\
\hline \multirow{2}{*}{$\begin{array}{l}\text { If your family member was ill or injured, would you (as a health care provider) want the } \\
\text { option to be present during Invasive procedure }\end{array}$} & Yes & 105 & 54.7 \\
\hline & No & 87 & 45.3 \\
\hline \multirow{2}{*}{$\begin{array}{l}\text { If your family member was ill or injured, would you (as a health care provider) want the } \\
\text { option to be present during CPR }\end{array}$} & Yes & 91 & 47.4 \\
\hline & No & 101 & 52.6 \\
\hline \multirow{2}{*}{$\begin{array}{l}\text { If your family member was ill or injured, do you feel other members of your family } \\
\text { (non-health care providers) should have the option to be present during invasive procedure }\end{array}$} & Yes & 73 & 38.0 \\
\hline & No & 119 & 62.0 \\
\hline \multirow{2}{*}{$\begin{array}{l}\text { If your family member was ill or injured, do you feel other members of your family } \\
\text { (non-health care providers) should have the option to be present during CPR }\end{array}$} & Yes & 68 & 35.4 \\
\hline & No & 124 & 64.6 \\
\hline \multirow{2}{*}{$\begin{array}{l}\text { If you were critically ill/injured would you want the option to have your family present at } \\
\text { your bedside }\end{array}$} & Yes & 131 & 68.2 \\
\hline & No & 61 & 31.8 \\
\hline
\end{tabular}

Table 4 presents staff attitudes towards family presence during CPR. Results showed that almost all nurses had been participating in a treatment situation in which a family member was present during the performance of: invasive procedure and $42.2 \%$ during the performance of CPR. About $59 \%$ of nurses confirmed that their job performance had been ham- pered by the presence of a patient's family member. In case of family member illness, $54.7 \%$ of nurses would choose to be present during an invasive procedure; however, $53 \%$ chose not to be present during CPR. About $68 \%$ of nurses would choose the option of family presence if they were critically ill or injured.

Table 4. Participants ability to provide psychological \& emotional support $(\mathrm{N}=192)$

\begin{tabular}{|c|c|c|c|c|c|c|c|}
\hline \multirow{2}{*}{ Questions } & Mean & SD & \multirow{2}{*}{ S. disagree } & \multirow{2}{*}{ Disagree } & \multirow{2}{*}{ Un-decided } & \multirow{2}{*}{ Agree } & \multirow{2}{*}{ S. agree } \\
\hline & $20.6 \mathrm{~s}$ & 3.872 & & & & & \\
\hline $\begin{array}{l}\text { Providing psychosocial and/or emotional support to family members } \\
\text { is part of my job/practice. }\end{array}$ & 4.16 & .913 & 70 & 102 & 7 & 6 & 7 \\
\hline $\begin{array}{l}\text { I feel comfortable providing psychosocial/emotional support to family } \\
\text { members during treatment situations. }\end{array}$ & 4.04 & .864 & 49 & 121 & 8 & 8 & 6 \\
\hline $\begin{array}{l}\text { I feel appropriate psychosocial/emotional care is provided to patients } \\
\text { and their family when patients are undergoing invasive procedures. }\end{array}$ & 3.85 & .911 & 44 & 95 & 36 & 14 & 3 \\
\hline $\begin{array}{l}\text { I feel appropriate psychosocial/emotional care is provided for family } \\
\text { members of patients undergoing resuscitation. }\end{array}$ & 3.66 & 1.00 & 34 & 90 & 45 & 14 & 9 \\
\hline $\begin{array}{l}\text { I believe family members should have the option to be present during } \\
\text { invasive procedures. }\end{array}$ & 2.51 & 1.27 & 13 & 44 & 17 & 71 & 47 \\
\hline $\begin{array}{l}\text { I believe family members should have the option to be present during } \\
\text { resuscitation situations. }\end{array}$ & 2.31 & 1.20 & 7 & 40 & 14 & 75 & 56 \\
\hline
\end{tabular}

Significant differences were found, according to gender categories $(t(190)=-2.254 ; p=.025)$. Female nurses had more positive attitudes toward family presence $(\mathrm{M}=20.88, S D$ = 3.62) than did male nurses $(\mathrm{M}=19.46, S D=4.36)$. No significant differences in attitudes were found between Saudi nurses and non-Saudi nurses $(F(3)=2.54, p=.57)$. However, attitudes toward family presence did differ significantly between nurses working in different hospital departments $(F(4)=6.37, p=.000)$. Post hoc analysis revealed that nurses who worked in the ICU department had significantly higher 
scores $(\mathrm{M}=21.1, S D=3.7)$ than did those who worked in the emergency department $(\mathrm{M}=18.9, S D=4.3)$. Previous participation in CPR courses revealed significant differences in nurses attitudes $(t(189)=2.06, p=.032)$. Nurses who attended CPR $(\mathrm{M}=21.4, S D=2.9)$ were more likely to support family presence than did who did not $(\mathrm{M}=20.1, S D=4.1)$. Significant differences also existed in attitudes among nurses who had family presences during CPR applied in their work $(t(190)=3.14, p=.002)$. Attitudes of nurses where option of family presence is applied scored higher $(\mathrm{M}=21.96, S D$ $=3.28$ ) compared to those where family presence option is not applied $(\mathrm{M}=20.00, S D=3.94)$.

\subsection{Nurses' concerns and barriers to support family presence during CPR}

Participants' responses were analyzed and the answers were compiled into themes. Several answers emerged from the open-ended question. A major concern of nurses was about the safety of patients and their families. The top comments were worries of fainting of family members, worries about family members fainting, distraction and interference with care, which are activities that may result in patient's poor quality of care if the nurses' care became diverted from patients to the patient's family members. Another concern was patients' family member's emotional responses. Nurses had worrying feelings that family members who eyewitness CPR would only remember the last moments of their loved ones or even traumatized by the experience. Because those moments are so emotional; nurses were worried that the psychological impact of these moments on family members may cause disruption to resuscitation.

In addition, some nurses expressed feeling of performance anxiety of being watched by family members and this could affect their team discussion during resuscitation and hence interfere with their decision-making. Some nurses thought that patients and family members do not understand what is involved in family presence and its limitations. A final concern was the need for customized tactics of use of family presence option. Some nurses believed that family presence tactics should vary in accordance with the age of patients and their conditions. Most nurses pointed out that family presence should be an option rather than a hospital policy, taking into consideration the age and the condition of patients.

\section{Discussion}

Our findings in this study add to the growing body of literature assessing healthcare provider's attitudes regarding family presence. To our knowledge, there is no formal study has reported about Saudi nurses' attitudes regarding family presence during CPR. The finding of this study showing that majority of nurses has positive attitudes toward family presence. ${ }^{[21,27]}$ However, there is incongruence with others' studies. ${ }^{[21,25]}$ Although scores of nurses' attitudes did not differ significantly between nurses working in different units (emergency department, ICU, CCU), more positive attitudes were seen among ICU nurses.

Nurses pointed out numerous concerns about family presence. A major concern was about the safety of patients and their families, which have been cited in the literature as a possible barrier to family presence ${ }^{[21,24,28]}$ The finding of this study not only supports this concern, but also some nurses think that family presence could not be helpful to both patients and families. In addition, some nurses thought that if family members understood what family presence is and that it did not hinder care provided, and then family presence would be appropriate.

Another concern by nurses was the emotional welfare of patients' family members which was considered as another barrier to family presence that might have psychological effects of being at family members' CPR. ${ }^{[2,21,23]}$ In this study, nurses assumed that family members might not tolerate the emotionally family presence, although $54 \%$ of nurses had asked the patients' families to be present during resuscitation. Nurses quoted performance anxiety as a concern to family presence, cited performance anxiety as a concern to family presence, a concern that is conveyed in other studies. ${ }^{[24,25]}$

The nurses stressed that family presence should be an option rather than policy depending on situations and whether it should be applied as a policy; hospital administrators should safeguard that guidelines are regularly followed during family presence. The positive attitudes toward family presence by nurses may be attributed to prior experience with family presence. In addition, two thirds of our sample was non Saudis. In Saudi, the rate of nurses is 21.1 nurses/10,000 people (one nurse for 473 people). Worth noting is that, the total number of nurses working in KSA is 51,188. The nonSaudi nurses is $28,598(56 \%)$, and 10,660 (21\%) are working in Riyadh region, 7,213 (68\%) of them are non-Saudi and 3,447 are Saudi, the percentage of female nurses working in Riyadh is $74 \% .{ }^{[29]}$ Therefore the findings of this study about family presence imply that family presence is becoming a more accepted practice. In order to enhance family presence, there is a need first for nurses to work through policy and procedure development to provide every patient and family with opportunities to decide regarding family presence, accommodate families at the bedside and address barriers that hinder the practice, and generate a hospital policy for family presence taking into account healthcare providers' concerns and supports them in their practice. 
The findings of this study should be interpreted in view of the limitations such as the self-report method of data collection, lack of information about participant prior experiences with family presence, and the effect of response bias since the sample was obtained using convenience method and from emergency department, ICU, and CCUs. Therefore it is possible that the nurses attending these units were more informed about family presence and motivated to undergo family presence than other units. To allow for more generalizability of findings, family presence should be studied in other specialty areas using. The high propensity family presence indicates a need for surveying patients, families, and healthcare providers about family presence and barriers. Surveying an ethnically diverse population would help to increase our knowledge if culture plays a role in the desire for family presence. Despite the limitations, this is the first study to document the attitudes of Saudi nurses in any health care setting and provide important insights into the attitudes among nurses regarding family presence.

\section{REFERENCES}

[1] American Association of Critical-Care Nurses. Practice alert: family presence during CPR and invasive procedures. 2007 [cited February, 2014]. Available from: http://www. aacn.org/AACN/practice Alert.nsf/vwdoc/pa2

[2] MacLean SL, Guzzetta CE, White C, et al. Family presence during cardiopulmonary resuscitation and invasive procedures: practices of critical care and emergency nurses. Journal of Emergency Nursing 2003; 29(3): 208. PMID:12776076. http://dx.doi.org/10.10 $67 /$ men. 2003. 100

[3] Henneman EA, Cardin S. Family-centered care: a practical approach to making it happen. Critical Care Nurse. 2002 December; 22: 12-16, 18-19. PMID:12518563.

[4] Leske JS. Needs of adult family members after critical illness: prescriptions for interventions. Critical Care Nursing Clinics of North America. 1992; 4: 587-596. PMID:1288581.

[5] Berns R, Colvin ER. The final story: events at the bedside of dying patients as told by survivors. ANNA Journal. 1998; 25: 583-587. PMID:10188391.

[6] Molter NC. Needs of relatives of critically ill patients: a descriptive study. Heart Lung. 1979; 8: 332-339. PMID:253712.

[7] Dudley NC, Hansen KW, Furnival RA, et al. The effect of family presence on the efficiency of pediatric trauma resuscitations. Annals of Emergency Medicine. 2009; 53(6): 777-784.

[8] Mortelmans LJM, Van Broeckhoven V, Van Boxstael S, et al. Patients' and relatives' view on witnessed resuscitation in the emergency department: A prospective study. European Journal of Emergency Medicine. 2009; 16: 2, 87-91. http://dx.doi.org/10.1097/M EJ.0b013e32830abe17 PMID:19262205.

[9] Piira T, Sugiura T, Champion GD, et al. The role of parental presence in the context of children's medical procedures: A systematic review. Child: Care, Health \& Development. 2005; 31(2): 233-243. http://dx.doi.org/10.1111/j.1365-2214.2004.00466.x

[10] Tinsley C, Hill JB, Shah J, et al. Experience of families during cardiopulmonary resuscitation in a pediatric intensive care unit. Pediatrics. 2008; 122(4): e799-804. http://dx.doi.org/10.1542/p eds. 2007-3650l PMID:18829777.

[11] Basol R, Ohman K, Simones J, et al. Using research to determine support for a policy on family presence during resuscitation. Dimensions in Critical Care Nursing. 2009; 28(5): 237-247. PMID:19700973. http://dx.doi.org/10.1097/DCC.0b013e3181ac4bf4

[12] Demir F. Presence of patients' families during cardiopulmonary resuscitation: Physicians' and nurses' opinions. Journal of Advanced Nursing. 2008; 63(4): 409-416. PMID:18727768. http: //dx.doi.org/10.1111/j.1365-2648.2008.04725.x
[13] Emergency Nurses Association. Presenting the option for family presence. (3rd ed.). Des Plaines, IL: 2007. Chapter 2: "Review of the Literature on Family Presence".

[14] Fallis WM, McClement S, Pereira A. Family presence during resuscitation: A survey of Canadian critical care nurses' practices and perceptions. Dynamics. 2008; 19(3): 22-28. PMID:18773712.

[15] Fernandez R, Compton S, Jones KA, et al. The presence of a family witness impacts physician performance during simulated medical codes. Critical Care Medicine. 2009; 37(6): 1956-1960. PMID:19384215. http://dx.doi.org/10.1097/CCM.0b013e3 $181 \mathrm{a} 00818$

[16] Kuzin JK, Yborra JG, Taylor MD, et al. Family-member presence during interventions in the intensive care unit: Perceptions of pediatric cardiac intensive care providers. Pediatrics. 2007; 120(4): e895-e901. PMID:17908745. http://dx.doi.org/10.1542/peds. 2006-2 943

[17] Madden, Condon C. Emergency nurses' current practices and understanding of family presence during CPR. Journal of Emergency Nursing. 2007; 33(5): 433-440. PMID:17884472. http://dx.doi . org/10.1016/j.jen. 2007.06 .024

[18] Nigrovic LE, McQueen AA, Neuman MI. Lumbar success rate is not influenced by family-member presence. Pediatrics. 2007; 120(4): e777-e782. PMID:17908735. http://dx.doi.org/10.1542/ped s. 2006-3442

[19] Pruitt LM, Johnson A, Elliott JC, et al. Parental presence during pediatric invasive procedures. Journal of Pediatric Health Care. 2008; 22(2): 120-127. PMID:18294581. http://dx.doi.org/10.1016 /j.pedhc. 2007.04 .008

[20] Walker W. Accident and emergency staff opinion of the effects of family presence during adult resuscitation: critical literature review. Journal of Advanced Nursing. 2007; 61(4): 348-362. PMID:18234033. http://dx.doi.org/10.1111/j.1365-2648.2007.04535.x

[21] Redley B, Hood K. Staff attitudes toward family presence during resuscitation. Accident and Emergency Nursing. 1996; 4: 145-151. http ://dx .doi .org/10.1016/S0965-2302(96) 90062-4

[22] Timmermans S. High touch in high tech: the presence of relatives and friends during resuscitative efforts. Scholarly Inquiry of Nursing Practice. 1997; 11: 153-173. PMID:9329276.

[23] Meyers TA, Eichhorn DJ, Guzzetta CE. Do families want to be present during CPR? A retrospective survey. Journal of Emergency Nursing. 1998; 24: 400-405. http://dx.doi.org/10.1016/S00 99-1767 (98) 70005-4

[24] Helmer SD, Smith SR, Dort JM, et al. Family presence during trauma resuscitation: a survey of AAST and ENA members. American Association for the Surgery of Trauma. Emergency Nurses Associa- 
tion. Journal of Trauma. 2000; 48: 1015-1024. PMID:10866245. http://dx.doi.org/10.1097/00005373-200006000-00004

[25] McClenathan BM, Torrington KG, Uyehara CF. Family member presence during cardiopulmonary resuscitation: a survey of US and international critical care professionals. Chest. 2002; 122: 2204-2211 PMID:12475864. http://dx.doi.org/10.1378/chest.122.6 .2204

[26] Ellison S. Nurses' Attitudes toward Family Presence during Resuscitative Efforts and Invasive Procedures. Journal of Emergency Nursing. 2003; 29(6): 515-521. PMID:14631338. http://dx.doi.org/10.
$1016 / j \cdot j e n .2003 .10 .001$

[27] Post H. Letting the family in during a code. Nursing. 1989; 19: 43-46. PMID:2927758. http://dx.doi.org/10.1097/00152193-198 903000-00020

[28] Belanger MA, Reed S. A rural community hospital's experience with family-witnessed resuscitation. Journal of Emergency Nursing. 1997; 23: 238-239 http://dx.doi.org/10.1016/S0099-1767 (97)9 0015-5

[29] Al-Harthi A. Director of Personnel in Health Affairs in Riyadh region: personal communication. 2008. 